\title{
MIÇANGAS E POLÍTICA TARËNO: ALGUMAS APROXIMAÇÕES
}

Beads and tarëno politics: some approaches

Cuentas y política tarëno: algunos enfoques

Cecília de Santarém Azevedo de Oliveira ${ }^{1}$

\section{Resumo:}

Neste artigo proponho olhar para os potes de miçangas das mulheres tarëno (Tiriyó, Katxuyana, Txikiyana, habitantes da Terra Indígena Parque do Tumucumaque, no norte do Pará) com vistas a destacar algumas relações importantes na política ameríndia, e como isto se fundamenta no contexto da festa. O texto aborda algumas características do sistema gráfico tarëno, a ligação intrínseca entre miçangas, construção de parcerias e generosidade, a importância do casal, mais do que do homem, no cotidiano da chefia na região. Procuro, com isso, evidenciar como a política ameríndia não se desassocia da estética própria desses povos, tendo a festa e a alteridade como seu local privilegiado de ativação.

Palavras-chave: Política; Festa; Tiriyó; Miçangas

\begin{abstract}
:
In this article, I propose to look at the bead pots of the Tarëno women (Tiriyó, Katxuyana, Txikiyana, inhabitants of the Parque do Tumucumaque Indigenous Territory, in northern Pará), highlighting important relations in Amerindian politics, and how these relations are built in the festivals. Thus, the text goes through the characteristics of the tarëno graphic system, the intrinsic connection between beads, the establishment of partnerships and generosity, and the importance of the couple, more than man, in the daily life of the chief in the region. Thus, I try to show how Amerindian politics is not dissociated from the aesthetics of these peoples, having the Festivals and Alterity as their privileged place of activation.
\end{abstract}

Keywords: Politics, Festivals, Tiriyó, beads

\footnotetext{
${ }^{1}$ Mestra em Antropologia Social pela Universidade de São Paulo (USP)/ Centro de Estudos Ameríndios (CestA/USP). Assessora indigenista junto ao lepé Instituto de Pesquisa e Formação Indígena. ceciliadesantarem@gmail.com
} 


\section{Resumen}

En este artículo, propongo mirar las vasijas de cuentas de las mujeres Tarëno (Tiriyó, Katxuyana, Txikiyana, habitantes del Territorio Indígena Parque do Tumucumaque, en el norte de Pará), destacando relaciones importantes en la política amerindia, entendida como fundamentada en momentos de fiestas. Así, el texto pasa por las características del sistema gráfico tarëno, la conexión intrínseca entre las cuentas de vidro, el establecimiento de alianzas y la generosidad, y la importancia de la pareja, más que del hombre, en la vida cotidiana del liderazgo de la región. Así trato de mostrar cómo la política amerindia no se disocia de la estética de estos pueblos, teniendo la Fiesta e Alteridad como su lugar privilegiado de activación.

Palabras clave: Política; Partido; Tiriyó; Cuentas de viseo

\section{Apresentação: na tukusipan e no pakara²}

Miçangas são objetos de alto apreço dos povos ameríndios - isto não é segredo para ninguém ${ }^{3}$. Por meio de variadas técnicas e combinações de cores, as miçangas de vidro constituem-se como expressão estética e estabelecimento de relações de parceria, circulando como bens de alto valor entre diferentes povos indígenas de todo o continente americano. No caso do sudeste guianense, entre os povos autodenominados Tarëno e reconhecidos, sobretudo, como Tiriyó, Katxuyana, Txikiyana, dentre outros, isso não é diferente.

Neste artigo, opto por me referir a eles como povos tarëno, e não tiriyó, katxuyana, txikiyana etc., por entender que isto valoriza a riqueza da sociodiversidade do contexto etnográfico em questão. Tarëno, como se autodesignam esses povos em língua tiriyó, significa, literalmente, "os daqui". O termo pode também designar outros povos indígenas, de modo que seu uso remete muito mais a uma determinada posição que a uma categoria identitária em $\mathrm{si}^{4}$. $\mathrm{Na}$ atualidade, os Tarëno vivem entre o Suriname e o Brasil, mais especificamente no norte do Pará. A reflexão que pauta o presente artigo se fundamenta no contexto brasileiro, a saber, em informações levantadas em minhas incursões a campo nas Terras Indígenas Parque do Tumucumaque e Rio Paru d'Este.

Em linhas gerais, as festas de Natal e as assembleias constituem ocasiões nas quais se vê a profusão de adornos feitos de miçangas: pessoas de todas as idades, crianças, homens e mulheres, ostentam pulseiras, brincos, colares, cintos e saias frontais de miçangas, além das tangas de tecido vermelho e das pinturas corporais à base de de jenipapo e urucum. Cocares de pluma também compõem o traje tradicional, assim como jarreteiras, braceletes e tornozeleiras. Com suas variações, tais vestimentas podem ser apreciadas entre os diferentes povos indígenas que habitam a região ${ }^{5}$.

São nessas ocasiões festivas e de importantes negociações, com a junção de pessoas da aldeia e visitantes de fora, que a tukusipan vê-se repleta de pessoas, miçangas, bebidas e eremi, os cantos e as danças

\footnotetext{
${ }^{2}$ Agradeço à Ana Yano, pela revisão atenta, e Dominique Gallois, pelos comentários e apoio.

${ }^{3}$ A exposição No Caminho da Miçanga: um mundo que se faz de contas, organizada pela antropóloga Els Lagrou, traz a diversidade das relações ameríndias com as miçangas. O catálogo da exposição (LAGROU, 2016) é referência fundamental para a minha pesquisa.

${ }^{4}$ Grupioni (2002), em sua tese de doutorado, demonstra de modo aprofundado como as diferentes gentes que compõem os Tarëno são concebidas de acordo com o seu sistema de mundos. De modo mais sintético, é possível vislumbrar tal complexidade no Plano de Gestão Territorial e Ambiental das Terras Indígenas Parque do Tumucumaque e Rio Paru d’Este (APITIKATXI, APIWA \& IEPÉ, 2018).

${ }^{5}$ Imagens dos trajes tradicionais tiriyó, aparai, katxuyana e wajãpi podem ser encontradas em minha dissertação de mestrado (OLIVEIRA, 2019, p.112-117)
} 
tradicionais dos povos tarëno. Tukusipan ${ }^{6}$ é o nome, em tiriyó, da casa central na qual os anfitriões das aldeias recebem seus visitantes; designa, também, um tipo específico de construção para essa casa central. No caso da aldeia Missão Tiriyó, o maior aldeamento da região, a tukusipan é referida como ëripowarae. Segundo me explicaram, isso dá devido sua forma remeter a colmeia de um determinado tipo de vespa, que não pude identificar, e que leva esse nome. Outro objeto cuja denominação veicula-se a esse tipo de colmeia é o torrador de beiju utilizado cotidianamente para as mulheres ${ }^{7}$.

Quando as mulheres tarëno abrem os recipientes nos quais guardam suas preciosas miçangas, é possível apreender, a partir da composição do conjunto e da diversidade das contas contidas em cada pote, as relações que permeiam tais objetos. Pertencentes ou não a enfeites, outrora, fiados ou tecidos, as miçangas carregam em si conhecimentos relativos aos repertórios gráficos - registros de uma estética ameríndia -, bem como a materialização de relações variadas, esparsas tanto no tempo quanto no espaço.

Se antes as miçangas eram enroladas em pedaços de tecido para serem armazenadas em pakarapisi, pequenos cestos retangulares, com tampa, tradicionais na região, nos dias de hoje costumam ser guardadas em recipientes ou sacos plásticos resistentes e colocadas dentro de potes vedados. Para maior segurança e privacidade, esses potes podem, ainda, ser guardados dentro de mochilas ou malas. A despeito do tipo de recipiente, é preferível sempre que as miçangas estejam fora da vista de outras pessoas e seguras das mãos (ou patas) alheias.

A posse de grandes quantidades de miçangas é um forte indício de que a pessoa (ou, antes, o casal) mantém boas e amplas parcerias de trocas. Miçangas são itens altamente apreciados pelos povos tarëno há pelo menos três séculos, conforme abordaremos adiante, e sua circulação está fortemente vinculada à presença dos pananakiri ou karaiwa (estrangeiros como brasileiros, franceses, holandeses, surinameses) e dos mekoro (grupos de descendentes de africanos escravizados e estabelecidos nas florestas do interior do Suriname, Guiana Francesa e Guiana). Atualmente o fluxo de miçangas é mais intenso nas cidades de Macapá ou Santarém, onde já é possível adquirir as miçangas mais apreciadas por esses povos, quais sejam, as de origem tcheca. Uma das vias de acesso a elas são as atividades e as oficinas de promoção e valorização cultural ${ }^{8}$ promovidas nas Terras Indígenas, bem como a comercialização realizada, principalmente, pelas mulheres que estão na cidade.

Certo dia, em conversa com Lurdes Kaxuyana, tive acesso aos antigos iyafan (bandoleiras) que pertenceram, outrora, ao seu falecido sogro, Matias Ape Tiriyó, destacado chefe e pajé da região do Tumucumaque. Algumas miçangas vieram de trocas com os mekoro, outras lhes foram dadas de presente pela antropóloga Denise Fajardo. O pote de miçangas de Lurdes é um balde de plástico, com tampa de boa vedação, muito comum na região e que tem servido de substituto ao pakara, cesto retangular com tampa, de trama bem fechada. Além das miçangas, ali está guardado um pedaço de um antigo panti (cinto) de seu marido, Tito Meri, vice-cacique da Missão Tiriyó, a principal aldeia da região. O pedaço de panti (cf. fig. 1) serve de modelo e inspiração para os novos cintos que Lurdes está tecendo para seus filhos, um deles professor destacado na escola da aldeia, o outro, presidente da APITIKATXI (Associação dos Povos Indígenas Tiriyó, Katxuyana e Txikiyana).

Abrir esse balde de miçangas, repleto, ainda, de tantos outros objetos, como agulhas, tesouras, miçangas e linhas, é adentrar em feixes de relações políticas, estendidas no tempo, estabelecidas e mantidas cotidianamente. É evidente que as festas e as assembleias não se resumem ao uso de adornos de miçangas.

\footnotetext{
${ }^{6}$ Para o caso wWyana, veriSchoepf (1998).

${ }^{7}$ A construção dessa casa foi possível graças àpeobilização da Articulação de Mulheres Indígenas Tiriyó, Katxuyana e Txikiyana (AMITIKATXI), que decidiu assim denominar seu Fundo de Artesanato: Wëri Ëripo ("torrador de beiju da mulher"), como uma forma de abreviação de Wëriton Ëripowarae ("casa das mulheres").
}

${ }^{8}$ Tais eventos são realizados com o apoio do lepé Instituto de Pesquisa e Formação Indígena, ao qual sou vinculada desde 2016. Na condição de assessora, Eu mesma faço parte dessa extensa rede de circulação de miçangast 


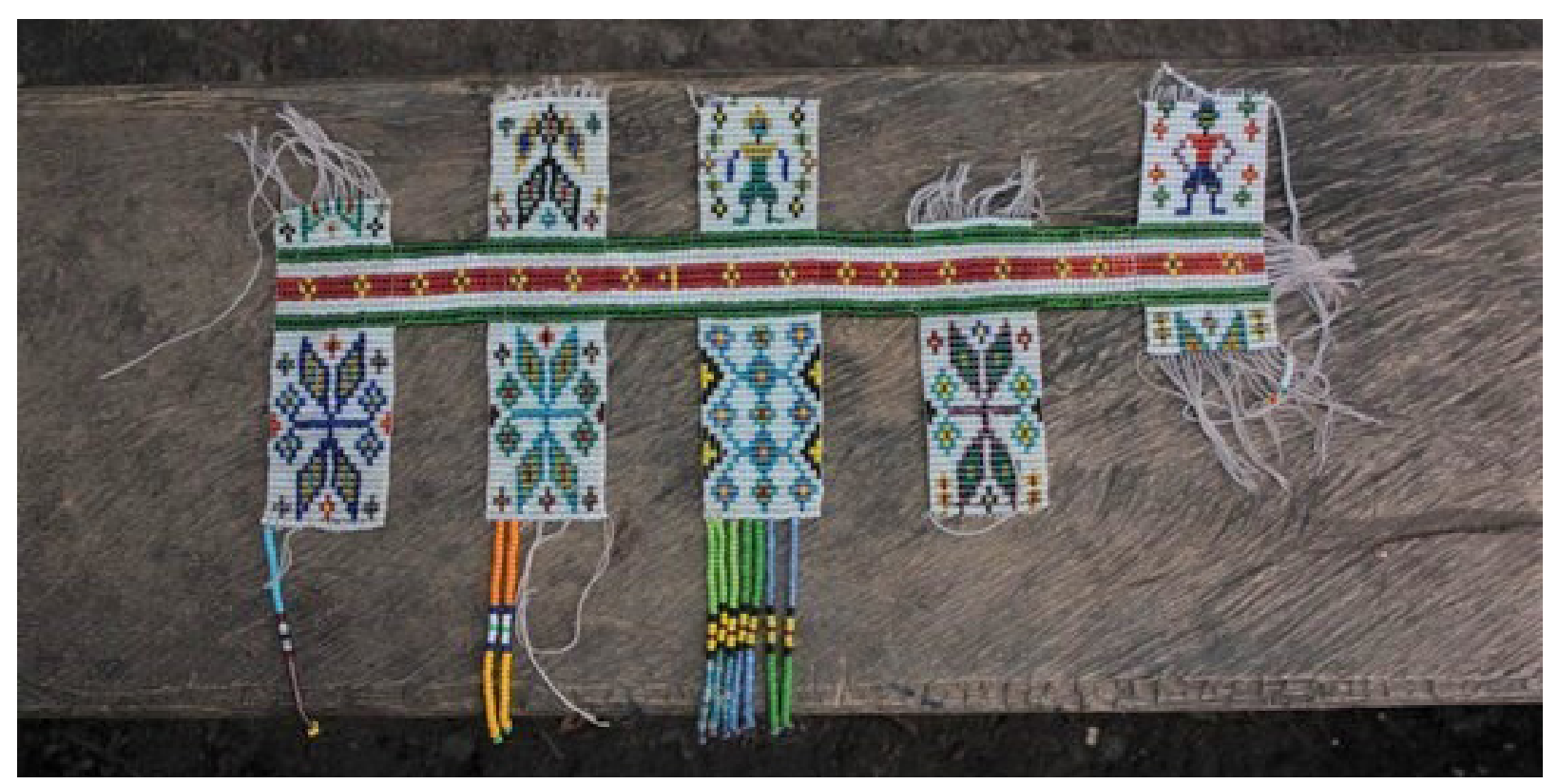

Figura 1 - Pedaço de panti (cinto masculino) guardado por Lurdes Kaxuyana. Fonte: Oliveira 2019: 73.

É notável, no entanto, que a presença e a ação desses enfeites nos permitem expandir o entendimento do que seria a política ameríndia, dado que a circulação desses objetos explicitam o estabelecimento de parcerias entre diferentes gentes e o princípio da generosidade, seja no cotidiano, seja nos momentos de festa.

\section{Padrões e contrastes nas artes visuais tarëno}

A ornamentação aparece, com destaque, como parte dos processos que se convencionou designar por fabricação corporal ameríndia (SEEGER et allii, 1979). Entre os povos tarëno, pinturas e adornos de diversos tipos e materiais sobressaem tanto no uso cotidiano quanto em momentos de efervescência política, como festas e assembleias.

Cabe às mulheres, sobretudo, se encarregarem das pinturas corporais e da produção de boa parte dos adornos, dedicando-se cotidianamente à feitura de adornos de miçangas. As tintas utilizadas na pintura corporal, notadamente o jenipapo ( cor vermelho-alaranjado), também são preparadas por elas com alguns dias de antecedência.

As pinturas são executadas calmamente pelas mulheres nos corpos de outras pessoas: no rosto (nariz, testa, bochechas, queixo), nos braços e antebraços, no tronco (peito, barriga e costas), nas pernas. Para a aplicação da tinta de jenipapo são usados vários tipos de pincéis, o que possibilita a execução precisa de traços finos ou grossos, únicos ou múltiplos. As mãos das mulheres tendem a ficar completamente tingidas, sobretudo se elas também tiverem preparado a tinta.

O repertório de grafismos que compõe as pinturas corporais é chamado imenutom e consiste em padrões geométricos observados e imitados dos corpos de diversos outros seres. É assim que temos ëkei imenu (desenho da cobra), ëkeimë taya imenu (desenho do pescoço da cobra sucuriju), kuriya imenu (desenho do jabuti), kïnïwï imenu (desenho da jiboia), paimeku imenu (desenho do pulso da anta), maraya kahto (desenho do ubim), nukë ema imenu (desenho do caminho do cupim), dentre tantos outros ${ }^{10}$. No mais das vezes, diferentes composições desses padrões resultam em um amplo repertório de pinturas corporais.

\footnotetext{
${ }^{9}$ Uma descrição sobre o modo de preparo da tinta de jenipapo pode ser encontrada em Grupioni (2009:64-67).
} 
Assim como outros povos indígenas da região ${ }^{11}$, os Tarëno remetem o aprendizado e a apreensão dos grafismos a encontros com alteridades tais como Cobras Grandes e inimigos de guerra, colocando, assim, a questão da autoria dos padrões gráficos em um regime de conhecimento marcado pela abertura ao outro, conforme destacou Lévi-Strauss em História de Lince (1991), bem como em outros trabalhos.

No caso dos grafismos utilizados pelos povos tarëno, é perceptível a centralidade da abertura ao outro pela incorporação daquilo que, em língua tiriyó, é chamado de $i k u h t u$, termo utilizado para fotografias e imagens figurativas, muitas delas retiradas de livros de ponto-cruz difundidos por missionários. É comum observar esse tipo de desenho nos panti, cintos masculinos. Algumas imagens que aparecem com frequência são leões, barcos, ordenha de vaca, helicóptero, dentre outras.

Em linhas gerais, as pinturas corporais à base da tinta de jenipapo exibem os grafismos tradicionais acima mencionados. No caso do rosto, é possível observar a aplicação de desenhos com traços grossos feitos de urucum, bem como a utilização de lápis de olho e batons de cores chamativas, como vermelho e roxo. Algumas mulheres jovens gostam de combinar os desenhos da testa e das maçãs do rosto com o uso de sombras de maquiagem adquiridas na cidade. É comum, também, desenharem suas sobrancelhas com lápis de olho.

De sua parte, os adornos de miçangas podem apresentar tanto elementos imenutom quanto $i k u$ tutom, muitas vezes misturando os tipos de grafismos em suas composições. Isto é, as peças em miçangas podem tanto trazer os grafismos tradicionais que aparecem nas pinturas corporais e cestarias, quanto imagens figurativas, ou mesmo escritos e imagens de bandeiras. Apenas nos keweyu (a saia frontal feminina) não se vê, jamais, os padrões $i k u h t u$. As miçangas, sem dúvida, são a expressão, por excelência, da criatividade das mulheres tarëno, tanto no que se refere às composições de desenhos, por meio do manejo dos referidos repertórios, quanto nas possibilidades oferecidas pela ampla gama de cores disponíveis.

Apesar da ausência, até o momento, de um estudo detalhado sobre as percepções das cores entre os povos indígenas das Terras Indígenas Parque do Tumucumaque e Rio Paru d’Este, as ponderações de van Velthem (2002) para os Wayana mostram-se igualmente válidas para os povos tarëno ${ }^{12}$. Vê-se que o contraste operado pelo preto e pelo vermelho nas pinturas corporais orienta as escolhas das cores para a feitura de peças de miçangas. Tal contraste é perceptível, por exemplo,na confecção dos iyafan (bandoleiras), comumente usados em pares de tons como laranja/vermelho e azul/verde, branco/amarelo e preto/azulão. São também essas cores que figuram como preferenciais nas encomendas de miçangas a pessoas que, como eu, têm acesso àquelas mais apreciadas pelas mulheres tarëno: as miçangas de vidro provenientes da República Tcheca.

\section{Obtendo miçangas: parcerias políticas}

As miçangas de vidro podem ser consideradas objetos estrangeiros por excelência, afinal aquelas mais apreciadas pelos povos ameríndios são, necessariamente, produzidas em indústrias - no caso, na região de Jablonex, na República Tcheca. A circulação desses objetos entre os povos indígenas é antiga, anterior mesmo à chegada de Cristóvão Colombo, conforme atestam os achados arqueológicos em sítios de ocupação viking, abandonados por volta de 1347, no leste canadense (DUBIN, 1987,p.271).

Na região do Parque do Tumucumaque e Rio Paru d'Este, foco do presente trabalho, as miçangas circulam há mais de trezentos anos (SCHOEPF, 1976, p.57) ${ }^{13}$. Ao longo dos séculos, intensos deslocamentos pelo

\footnotetext{
${ }^{10}$ Grupioni (2009) apresenta um amplo repertório desses padrões.

${ }^{11}$ Para os Wayana e Aparai, cf.vean Velthem (2002) e van Velthem \& Linke (2010); para os Wajãpi, cf. vellois (2002).

${ }^{12}$ Dependendo do referencial adotado, os Wayana também são considerados Tarëno pelos falantes de língua tiriyó.
} 
continente sul-americano resultaram em aproximações e distanciamentos entre diferentes grupos e, por extensão, em uma atualização constante das parcerias de troca. No século XVII, a intensidade das relações com os não-indígenas deu-se no litoral norte dos atuais Suriname e Guiana Francesa, conforme nos relatam os escritos do Padre Jean de la Mousse (LA MOUSSE \& COLLOMB, 2006), nos quais já encontramos menção ao apreço indígena pelas rassades, fieiras de miçangas oferecidas pelo padre no intento de convertê-los ao catecismo.

Nos séculos XVIII e XIX, a aquisição de miçangas se dava, preferencialmente, com os mekoro, grupos descendentes de africanos escravizados e trazidos à América. As imbricadas redes de trocas de objetos, conhecimentos e pessoas (via casamentos) na região, abordadas em Gallois (2005), culminaram no deslocamento das miçangas, então obtidas junto aos europeus no litoral, rumo às florestas, dessa vez o mekoro, servindo de troca por bens diversos, como adornos plumários e pimentas (BARBOSA 2002, 2007). A entrada no interior do continente deu-se por redes de intercâmbio, conforme os grupos estabeleciam relações com outros povos indígenas. É por isso, por exemplo, que ouvi de um senhor katuena, nascido nas cabeceiras do rio Trombetas (Pará) e com quem conversei às margens do rio Jatapu (Roraima), que eles conseguiam as miçangas com os Tiriyó. Os Tiriyó, por sua vez, costumam apontar os mekoro como seus primeiros fornecedores de miçangas, as quais eram trocadas por cachorros de caça (BARBOSA, 2007:102).

No relato de Jules Crevaux (1883) encontramos uma prancha ilustrativa de uma casa galibi repleta dos mais diversos objetos: rede, cerâmica, borduna, tanga de miçangas, flechas etc.. É interessante notar que a possibilidade dos objetos serem oriundos de trocas é igualmente significativa para os povos indígenas, como pude perceber ao mostrar a ilustração para Merekuku Aparay e lhe perguntar se aqueles objetos eram mesmo dos Galibi. Merekuku Aparay considerou que eles poderiam ter trocado com alguém, evidenciando como a riqueza de uma casa cheia de objetos atesta não apenas a posse de todos eles, mas, sobretudo, as relações estabelecidas com outras pessoas.

O século XX é marcado pela intensificação da relação dos povos indígenas da região com os Estados Nacionais e as missões cristãs (GALLOIS, 1983; GRUPIONI \& ANDRADE, 2015), em especial a partir da década de 1960, quando as missões evangélicas e católica estabeleceram-se em pontos estratégicos de ambos os lados das fronteiras, iniciando, com isso, um processo de centralização da população indígena em alguns aldeamentos. É assim que, de pequenas aldeias espalhadas pelas cabeceiras de igarapés, o cenário passa a ser o de grandes aldeias centralizadoras ${ }^{14}$.

Na região da Missão Tiriyó, aldeamento católico mobilizado, a princípio, por uma Missão Franciscana de origem alemã, e até hoje o local de maior concentração populacional da região, as miçangas passaram a ser obtidas diretamente com os freis, e não mais com os mekoro. É possível que parte significativa das coleções etnográficas referentes aos Tiriyó e aos Katxuyana disponíveis no Museu Paraense Emílio Goeldi seja proveniente desses intercâmbios, sendo o principal coletor o próprio Protásio Frikel. O mesmo se aplica às coleções pertencentes a museus europeus, como podemos ver em Kieffer-Døssing (2016) sobre as coleções localizadas na Dinamarca.

Atualmente as miçangas são obtidas por meio de pessoas que circulam por diferentes cidades brasileiras, em especial Macapá e São Paulo, oriundas das Terras Indígenas e que estejam na cidade de Macapá por variados motivos, seja para estudar, realizar tratamento de saúde, regularizar documentos, visitar os familiares etc. As miçangas disponíveis na cidade de Macapá, no entanto, costumam ser de origem chinesa, menos resistentes e de menor qualidade tanto no material quanto em sua coloração (tendem a desbotar), além de não terem tamanho e formato uniformes.

\footnotetext{
${ }^{13}$ Uma discussão mais aprofundada a respeito pode ser encontrada em Oliveira (2019).

${ }^{14}$ Tal movimento é perceptível nos mapas cronológicos publicados por Frikel (1971), também disponíveis no Plano de Gestão Territorial e Ambiental das Terras Indígenas Parque do Tumucumaque e Rio Paru d'Este (APITIKATXI, APIWA \& IEPÉ, 2018, p.45).
} 
Mesmo as pessoas oriundas das Terras Indígenas que estão em Macapá tendem a acionar suas parcerias, principalmente do sudeste do Brasil, para a aquisição das estimadas miçangas tchecas, comumente compradas diretamente de sua importadora nas proximidades da Rua 25 de Março, no centro da capital paulista. Assim, é por meio do estabelecimento de relações com pessoas detêm o acesso a esses objetos de melhor qualidade que é possível, por extensão, adquirir maiores quantidades de miçangas ${ }^{15}$.

A partir do apresentado, é possível perceber que as parcerias de trocas não permanecem as mesmas ao longo do tempo, assim como o fluxo de circulação de objetos (e, por conseguinte, de conhecimentos a eles relacionados), modificando e sendo modificado pelos padrões de ocupação populacional,pelas parcerias indígenas e não-indígenas disponíveis, entre outros fatores.

Nesta seção, procurei destacar como a aquisição de miçangas evidencia a capacidade das mulheres tarëno de firmar boas relações com parceiros estrangeiros, considerando especialmente as articulações necessárias para obter contas provenientes de lugares longínquos e como isto repercute no interior da aldeia. Afinal a produção de adornos de miçangas raramente se destina ao uso próprio, como veremos a seguir.

\section{Atenção à generosidade enquanto "chefia estendida"}

Apesar das mulheres tarëno serem tanto ciumentas quanto zelosas com seus potes de miçangas, não se vê nenhuma mulher fazendo uso ostensivo e exclusivo nem de suas miçangas e de outros materiais, nem dos adornos por ela produzidos. Destaca-se, aqui, a ética da generosidade como um princípio fundamental nas relações construídas por meio das miçangas, o que nos permite traçar um paralelo entre as características apreciadas no chefe ameríndio (PERRONE-MOISÉS, 2011, 2015) e aquelas que conformam a ética circulante entre as mulheres tarëno.

Embora persista certa centralidade do homem como figura de chefia, parece-nos adequado considerar o casal como o centro das relações políticas indígenas (PERRONE-MOISÉS, 2015). Não só pelo comportamento pautado na generosidade, mas também por tudo que permeia as regras de casamento na região, cuja tese de doutoramento de Denise Fajardo Grupioni (2002) analisa com rigor. Apesar de frequentemente enfatizarem a figura do homem tarëno como um pataentu, isto é, "dono da aldeia", "fonte da aldeia", não é raro encontrar situações em que são as mulheres (esposas ou irmãs) do pataentu assumindo a frente da aldeia, ainda que não seja muito recorrente, por exemplo, elas serem convidadas a participar dos encontros de caciques que ocorrem pelo menos uma vez por ano na região.

De todo modo, reforço que a generosidade esperada do pataentu estende-se à sua esposa, a qual não será bem vista caso não compartilhe suas miçangas com as demais mulheres. Durante a minha pesquisa de campo para o mestrado, por exemplo, eu dispunha de pouco tempo e poucos recursos para a realização do campo, e considerava mais plausível me hospedar em apenas uma aldeia, visando algum aprofundamento na situação cotidiana do local. Contudo, tão logo consultei a Associação e o cacique da aldeia principal, ele e sua esposa encabeçaram uma mobilização e ofereceram condições para que eu visitasse outras aldeias dos arredores, evitando, assim, qualquer constrangimento e a acusação de sovinar as miçangas que eu levava comigo.

A ojeriza que os povos ameríndios, em geral, demonstram em relação à avareza (PERRONE-MOISÉS, 2015,p.46) é explícita no que concerne às miçangas. Marubo (2016, p. 102) destaca as falas de um pajé que tenta alertar seus parentes para o perigo que as miçangas exercem, em especial sobre as mulheres,

\footnotetext{
${ }^{15}$ Desde o ano passado,a AMITIKATXI (Articulação das Mulheres Indígenas Tiriyó, Katxuyana e Txikiyana) tem retomado as atividades de fortalecimento cultural, em especial no que tange os conhecimentos de tecelagem de miçangas, aor meio de parcerias com o lepé.
} 
despertando a inveja entre elas. O cuidado para não se deixar levar pela vontade de passar o tempo todo tecendo miçangas também é destacado pelas mulheres tiriyó e katxuyana como um comportamento prudente. O fascínio das miçangas pode despertar alguns comportamentos considerados extravagantes pelos padrões de comedimento defendidos por vários povos indígenas ${ }^{16}$, sendo esses perigos (os quais podemos identificar como avareza e obsessão) aparentemente restritos às mulheres.

Apesar disso, espera-se que a generosidade vigore em boa parte das relações estabelecidas nos núcleos familiares. Entre os Tarëno, é comum as mulheres, em especial as mais velhas, não conseguirem concluir os trabalhos que demandam quantidades maiores de miçangas (como a confecção de keweyu e panti) por entregarem suas miçangas para as filhas e netas. Tal distribuição não se restringe às miçangas em si, posto que raramente uma mulher faz algum adorno para uso próprio: de modo geral, os enfeites são oferecidos para seus filhos, netos, maridos e pessoas com quem constrói parcerias, além de muitas peças serem destinadas à comercialização - atividade esta considerada bastante eficaz para a obtenção de mais miçangas.

\section{Estética política atualizada: guerras, festas e miçangas}

Não é necessário passar muito tempo numa aldeia da região das Terras Indígenas Parque do Tumucumaque e Rio Paru d'Este para perceber o quanto o momento da sakura é apreciado. Sakura é uma designação comum às diversas bebidas produzidas na região a partir da fermentação de variedades de mandiocas, batatas e carás, sendo diversos também os tipos de preparo e de produtos finais ${ }^{17}$. Há períodos em que os Tarëno se encontram diariamente para beber sakura em algum lugar da aldeia. Embora seja comum a presença da bebida em encontros festivos como aniversários, o mais frequente é compartilhá-la com pessoas que estejam colaborando em alguma atividade coletiva na aldeia, como mutirões para a abertura de roças, construção de casas, reparo de telhados etc. Assim, bebe-se sakura para o preparo das roças, e roças são feitas para que seja possível produzir bastante sakura.

No caso de samura (designação em língua tiriyó para miçanga, provavelmente fazendo alusão à samu, areia, destacando sua pequenez e profusão), a mesma lógica parece operar no que diz respeito à comercialização dos enfeites feitos de miçangas: o intuito das mulheres tarëno não parece ser a obtenção de dinheiro, mas sim a aquisição de mais miçangas para a confecção de mais adornos, e assim por diante. Muitos presentes ofertados por elas aos não-indígenas também são acompanhados da demandas por miçangas em cores e tamanhos específicos, além de agulhas e materiais como anzóis de brincos. Ainda que em determinadas situações algumas mulheres prefiram receber o pagamento em dinheiro, sobretudo quando estão na cidade, é comum que a produção de miçangas vise a obtenção de mais miçangas com vistas a dar continuidade aos seus conhecimentos tradicionais, como vem sendo enfatizado nas reuniões de articulação das mulheres tarëno.

A continuidade, uma das traduções possíveis para itïpï, é um dos cernes do sistema de pensamento tarëno (Grupioni 2002). Trata-se de uma das principais características da noção de pessoa na região, visto que cada pessoa é concebida como a continuação das gentes que a conformam (GRUPIONI, 2002:3): cada pessoa pode ser localizada, no tempo, em relação a sua itïpï, e espacialmente em relação a sua pata (aldeia). A argumentação das mulheres acerca da importância de adquirir grandes quantidades de miçangas para

\footnotetext{
${ }^{16}$ Sobre isso, eEtre os Shipino-Konibo, cf.vBelaunde (2016).; Vera Marubo (2016) traz relatos a respeito para os Marubo.

${ }^{17}$ Os diferentes tipos de bebidas recebem também designações específicas, variando conforme seu preparo e seu ingredientes, como paya, bebida kahyana que envolve inclusive a utilização de umtipo específico de fungo, não sendo nosso foco no presente artigo.
} 
que seus conhecimentos tenham continuidade entre suas filhas e netas pode ser vista como um paralelo da reflexão acima mencionada, articulando, assim, materialidade e imaterialidade.

As itï̈ï dizem respeito às diferentes yana (gente) da região: Aramayana, Pïrouyana, Aramiso, Katxuyana, Okomoyana, para mencionar alguns exemplos das autodesignações que por ali circulam. São as gente-macaco aranha, gente-flecha, gente-juruti, gente-do rio Katxuru, gente-vespa, dentre tantas outras, cujas relações datam de tempos imemoriais, por meio de sucessivas guerras, casamentos e outros tipos de parcerias. É no cotidiano de cada aldeia que essas diferentes gentes se relacionam, num movimento crescente de autovalorização de sua sociodiversidade, após período das concentrações populacionais provocadas por influência estatal e religiosa, onde a supressão dessa sociodiversidade aparece como uma das mais impactantes consequências (GRUPIONI, 2015; FRIKEL, 1958, 1971; APITIKATXI, APIWA \& IEPÉ, 2018).

Nas narrativas que me foram contadas por Peti Tiriyó na aldeia Oroientu, o uso das miçangas tornou-se massivo não a partir de um determinado contato com os não-indígenas, mas sim quando pïyai (pajé) consegue ver, dentro de uma montanha, uma grande festa com variados animais, todos cobertos de adornos e pinturas corporais, dançando, bebendo e cantando. A partir desta visão, pïyai passa a convencer os povos tarëno a parar com tantas guerras, pois acabariam dizimando uns aos outros. As miçangas que antes eram consideradas pesadas demais para serem usadas durante as guerras, passam, então, a integrar o centro das manifestações políticas tarëno - a saber, as festas. No presente caso, esses objetos aparecem nas narrativas como partes do processo em que se deixam para trás as guerras incessantes, dando início ao tempo das festas plenas de bebedeira, cantos, danças e adornos.

As guerras tornando-se festas: esse contínuo tão claramente exposto por Beatriz Perrone-Moisés (2015), em que a autora parte exatamente do sudeste guianense (a partir de sua experiência de campo junto aos Aparai), situa a festa como o lugar por excelência da política ameríndia, intrinsecamente ligada à produção cotidiana de corpos e de relações, conforme os povos tarëno nos demonstram por meio de seus usos das miçangas.

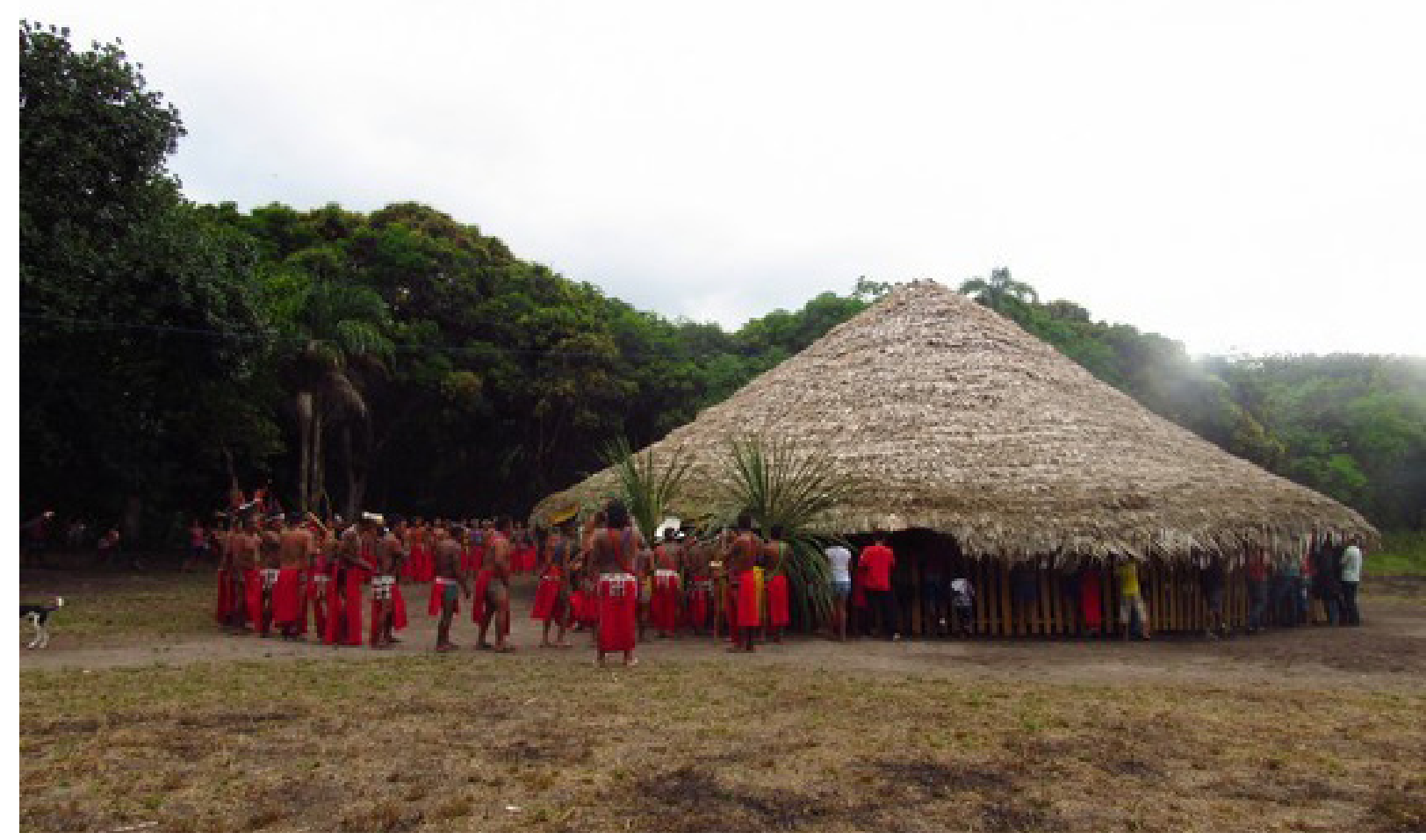

Figura 2 - Entrando na tukusipan, durante abertura da Assembleia da APITIKATXI, na aldeia Missão Tiriyó, com danças, miçangas e sakura. Novembro de 2019. Fonte: Acervo lepé/ Cecília de Santarém. 


\section{Conclusão}

Adentrar a tukusipan num momento de Assembleia é se deparar com profusões de miçangas, danças e pessoas de todas as aldeias do lado oeste da Terra Indígena Parque do Tumucumaque. A diversidade de adornos confeccionados com miçangas, bem como a presença de diferentes tipos de cocares e outros adornos, não deixa dúvida do quanto a estética dos povos tarëno valoriza a construção de relações, seja com as pessoas de fora (com as quais têm acesso às desejadas miçangas), seja com as de dentro (em especial, as mulheres detentoras dos saberes relativos à confecção dos adornos). As Assembleias, necessariamente, têm início com muitos adornos, cantos e danças, encerrando-se da mesma forma - ao fim, no entanto, estão todos autorizados a compartilhar a bebida sakura, até então interditada. São dias de muita resistência para enfrentar horas praticamente ininterruptas de discussões com órgãos governamentais, como as Secretarias de Saúde e de Educação Indígena. As miçangas, aqui, também são a expressão das culturas tiriyó, katxuyana e txikiyana, estratégia para que sejam reconhecidos de modo diferenciado pelo estado brasileiro. Valorizar o estabelecimento de parcerias e a generosidade: eis o que os povos tarëno fazem questão de enfatizar nesses encontros com esse Outro tão penoso de se relacionar.

\section{Referências}

APITIKATXI; APIWA; IEPÉ. Plano de Gestão Territorial e Ambiental das Terras Indígenas Parque do Tumucumaque e Rio Paru d’Este. São Paulo: Iepé, 2018.

BARBOSA, Gabriel Coutinho. Formas de intercâmbio, circulação de bens e a (re)produção das redes de relações aparai e wayana. Dissertação de Mestrado, PPGAS/USP, São Paulo, 2002.

BARBOSA, Gabriel Coutinho. Os Aparai, os Wayana e suas redes de intercâmbio. Tese de Doutoramento em Antropologia Social, PPGAS/USP, São Paulo, 2007.

BELAUNDE, Luísa Elvira. Chaquiras Shipibo-konibo. In: LAGROU, Elsje (Org.). No caminho da miçanga: um mundo que se faz de contas. Rio de Janeiro: Museu do Índio/Funai, 2016, p. 92-99.

CREVAUX, Docteur J. Voyages dans l' Amérique du Sud. Revised Second Edition edition. [s.l.]: Librairie Hachette et Cie., 1883. Disponível em: https://archive.org/details/voyagesdanslam00crevuoft/page/11 [Acesso 01 de outubro de 2019]

DUBIN, Lois Sherr. The History of Beads: From 30,000 B.C. to the Present. New York: Harry N. Abrams, 1987.

FRIKEL, Protásio. Classificação lingüistico-etnologia das tribos indígenas do Pará setentrional e zonas adjacentes. Revista de Antropologia, v. 6, n. 2, p. 113, 1958.

FRIKEL, Protásio. Dez anos de aculturação Tiriyó: 1960-70. 1971. Disponível em: <http://repositorio.museu-goeldi.br:8080/jspui/handle/mgoeldi/895>. Acesso em: 30 set. 2019

GALLOIS, Dominique Tilkin. Povos Indígenas no Brasil: Amapá/Norte do Pará. São Paulo: CEDI, 1983.

GALLOIS, Dominique Tilkin Gallois. Kusiwa: pintura corporal e arte gráfica wajãpi. Rio de Janeiro: Museu do Índio-Funai/APINA/CTI/NHII-USP, 2002.

GALLOIS, Dominique Tilkin (Org.). Redes de Relações nas Guianas. São Paulo: Humanitas/Fapesp, 2005.

GRUPIONI, Denise Fajardo; ANDRADE, Lúcia M. M. de (Orgs.). Entre Águas Bravas e Mansas. São Paulo: CPI-SP e Iepé, 2015. Disponível em: <http://cpisp.org.br/publicacao/entre-aguas-bravas-e-mansas/>. Acesso em: 7 out. 2019. 
GRUPIONI, Denise Fajardo. Sistema e mundo da vida tarëno: um "Jardim de veredas que se bifurcam" na paisagem guianesa. Tese de Doutoramento em Antropologia Social, PPGAS/USP, São Paulo, 2002.

GRUPIONI, Denise Fajardo. Tempo e espaço na Guiana Indígena. In: GALLOIS, Dominique Tilkin (Org.). Redes de Relações nas Guianas. São Paulo: Humanitas/Fapesp, 2005.

GRUPIONI, Denise Fajardo. Arte Visual Tiriyó e Kaxuyana: padrões de uma estética ameríndia. São Paulo: Iepé, 2009.

GRUPIONI, Denise Fajardo. Tiriyó/Katxuyana: os fios, as contas e as gotas. In: LAGROU, Elsje (Org.). Catálogo da Exposição No Caminho da Miçanga: um mundo que se faz de contas. Rio de Janeiro: Museu do Îndio/Funai, 2016, p. 185-194.

IPHAN, Instituto do Patrimônio Histórico e Artístico Nacional. Arte Kusiwa: pintura corporal e arte gráfica Wajãpi. Brasília, DF: Instituto do Patrimônio Histórico e Artístico Nacional. IPHAN, 2008.

KIEFFER-DØSSING, Astrid. Re-assembling the Katxuyana collections: An analysis of past, present and possible futures of the Katxuyana collections as assemblages. Dissertação de Mestrado, Aarhus Universitet, 2016.

LA MOUSSE, Jean de; COLLOMB, Gérard. Les indiens de la Sinnamary: journal du père Jean de La Mousse en Guyane, 1684-1691. Paris: Chandeigne, 2006. (Collection Magellane)

LAGROU, ELSJE (Org.). No caminho da miçanga: um mundo que se faz de contas. Rio de Janeiro: Museu do Índio/Funai, 2016.

LÉVI-STRAUSS, Claude. Histoire de Lynx. Paris: Plon, 1991.

MARUBO, Varin Mena. A desconfiança da miçanga: os Txakiri dos Marubo. In: LAGROU, Elsje (Org.). Catálogo da Exposição No Caminho da Miçangas: um mundo que se faz de contas. Rio de Janeiro: Museu do Índio/ Funai, 2016, p. 100-104

OLIVEIRA, Cecília de Santarém Azevedo de. Fios e tramas de miçangas: tecendo relações na Guiana Indígena. 2019. Dissertação (Mestrado em Antropologia Social) - Faculdade de Filosofia, Letras e Ciências Humanas, Universidade de São Paulo, São Paulo, 2019. doi:10.11606/D.8.2020.tde-13052020-190232. Acesso em: 2020-07-28.

PERRONE-MOISÉS, Beatriz. Bons chefes, maus chefes, chefões: elementos de filosofia política ameríndia. Revista de Antropologia, v. 54, n. 2, p. 857-883, 2011.

PERRONE-MOISÉS, Beatriz. Festa e Guerra. Livre-Docência, Universidade de São Paulo, São Paulo, 2015.

SCHOEPF, Daniel. Le japu faiseur de perles: Un mythe des Indiens Wayana Aparai du Bresil. [s.l.]: Musee d'Ethnographie, 1976

SCHOEPF, Daniel. Le domaine des colibris: accueil et hospitalité chez les Wayana (région des Guyanes). Journal de la Société des Américanistes. Tome $84 \mathrm{n}^{\circ} 1,1998$. pp. 99-120. Disponível em: < www.persee.fr/doc/jsa_00379174_1998_num_84_1_1771 >. Acesso em 30 de outubro de 2020.

SEEGER, Anthony; DA MATTA, Roberto; VIVEIROS DE CASTRO, Eduardo. A construção da pessoa nas sociedades indígenas brasileiras. Boletim do Museu Nacional, n. 32, p. 2-19, 1979.

VAN VELTHEM, Lúcia Hussak. O Belo é a Fera - a estética da predação e da produção entre os Wayana. Lisboa: Museu Nacional de Etnologia Assirio \& Alvim, 2003. Disponível em: $<$ http://www.livrariacultura.com.br/p/o-belo-e-a-fera-1347634>. Acesso em: 19 ago. 2015.

Recebido em 31/10/2020

Aceito em 23/11/2020 
